\title{
Studi Perbaikan Tempat Penyimpanan Sementara (TPS) Limbah B3 Sesuai Dengan Limbah Yang Dihasilkan Dan Peraturan Terbaru Di PT. $\mathbf{X}$
}

\author{
Ahmad Erlan Afiuddin1, Arga Kurniawan Dwi2 \\ 1Teknik Pengolahan Limbah, Politeknik Perkapalan Negeri Surabaya \\ 2Teknik Keselamatan Kesehatan Kerja, Politeknik Perkapalan Negeri \\ Surabaya \\ erlan.ahmad@gmail.com
}

\begin{abstract}
Abstrak
PT.X adalah perusahaan yang bergerak dibidang pemurnian minyak mentah, kapasitas produksi yang dihasilkan 32.000 BOPD. PT.X menghasilkan jenis limbah B3 yaitu: water waste, chemical waste, oil waste, empty drum waste, solid waste dan sulfatreat waste. PT. X memiliki TPS Limbah B3 yang belum sesuai dengan aturan, karena itu akan dilakukan studi perbaikan TPS Limbah B3. Studi peningkatan TPS limbah B3 diawali dengan pengambilan data limbah B3. Pengolahan data berupa evaluasi dan perancangan ulang sesuai dengan PP 101 tahun 2014, diantaranya adalah: pengemasan, pencahayaan, ventilasi, APAR, bak penampung, tata letak dan housekeeping. Sesuai hasil studi didapatkan kebutuhan penerangan pada TPS sebanyak 20 lampu (lampu pijar 300W). Total luas bukaan (ventilasi) yang dibutuhkan adalah $14,01 \mathrm{~m}^{2}$. Jumlah kebutuhan APAR yaitu 3 buah. Volume bak penampungan pada setiap ruangan limbah cair yaitu $17 \mathrm{~m}^{2}$ untuk water waste room, $3,88 \mathrm{~m}^{2}$ untuk chemical waste room dan $4,09 \mathrm{~m}^{2}$ untuk oil waste room. Housekeeping TPS perlu dilakukan untuk mengelola tempat kerja menjadi lebih baik lagi.
\end{abstract}

Kata kunci: TPS, Limbah dan B3

\section{PENDAHULUAN}

Limbah merupakan suatu materi yang tidak digunakan, tidak terpakai, tidak disenangi, atau sesuatu yang dibuang yang berasal dari kegiatan manusia. Pengelolaan limbah yang kurang baik dapat memberikan pengaruh negatif terhadap kesehatan [1] . PT.X hanya memiliki satu TPS (luas $178,5 \mathrm{~m}^{2}$ ) untuk menyimpan limbah B3, dan faktanya TPS tersebut tidak cukup untuk menampung seluruh limbah B3. Selain itu TPS PT X belum menerapkan pendataan limbah B3 yang baik.

Pada area TPS terdapat berbagai macam limbah : water waste, oil waste, sulfatreat waste, solid waste, chemical waste, dan empty drum waste. Fakta di lapangan ditemui beberapa bag sulfatreat waste tersimpan di luar area TPS. Kondisi tersebut tidak sesuai dengan Keputusan Bupati Bojonegoro No:188/56/Kep/ 412.11/2013 (izin penyimpanan sementara limbah B3 kepada Mobil Cepu Limited) [2] , "Menghindari tumpahan, ceceran dan jenis-jenis limbah B3 yang disimpan khususnya mudah terbakar atau meledak dan melakukan prosedur housekeeping yang baik”.

Ketidaksesuaian pengelolaan limbah B3 lainnya yang merujuk ke PP No.101 Tahun 2014 yaitu : TPS tidak memiliki dinding, limbah B3 terletak di luar area TPS, limbah B3 belum dikelompokkan dengan baik, simbol dan label B3 belum sesuai dan lain sebagainya. Oleh karena itu peneliti mencoba mengevaluasi TPS limbah B3 dan menyesuaikan dengan limbah yang dihasilkan serta sesuai dengan peraturan yang berlaku. Hal tersebut dilakukan dengan harapan agar terwujud sistem pengelolaan limbah B3 yang modern dan lebih baik lagi [3].

\section{TINJAUAN PUSTAKA}

\subsection{Limbah B3}

Menurut PP No.101 Tahun 2014, limbah B3 yaitu sisa suatu usaha dan/atau kegiatan yang mengandung zat, energi, dan/atau komponen lain yang karena sifat, konsentrasi, dan/atau jumlahnya, baik secara langsung maupun tidak, dapat mencemarkan dan/atau merusak lingkungan hidup, dan/atau membahayakan lingkungan hidup, kesehatan, serta kelangsungan hidup manusia dan makhluk hidup lain. Berdasarkan PP No.101 Tahun 2014 limbah B3 dapat diidentifikasi menurut sumber dan kategori bahayanya. Penjelasan detail mengenai identifikasi limbah B3 dapat dilihat pada poin-poin penjelasan pada PP No.101 Tahuhn 2014. 
Berdasarkan KEPKA BAPEDAL No.01/ BAPEDAL/09/1995 tentang tata cara dan persyaratan teknis penyimpanan dan pengumpulan limbah B3, jika kegiatan pengolahan limbah B3 belum dapat dilakukan dengan segera, maka perlu untuk melakukan penyimpanan limbah B3 terlebih dahulu[4]. Tujuan dari kegiatan penyimpanan adalah untuk mencegah terlepasnya limbah B3 ke lingkungan. Penyimpanan tersebut dilakukan dengan cara mengemas dan memberi label sesuai dengan jenis karakteristik limbah. Penjelasan lebih detail mengenai prinsip pengemasan limbah B3 (syarat pra-pengemasan, syarat umum kemasan, prinsip pengemasan limbah B3), tata cara pengemasan atau pewadahan limbah B3, tata cara penyimpanan limbah B3, persyaratan bangunan dan lokasi penyimpanan limbah B3 telah diatur dalam KEPKA BAPEDAL No.01/BAPEDAL/09/1995.

\subsection{Simbol, Label dan Bak Penampung Limbah B3}

Pemberian simbol dan label sangat penting untuk mengidentifikasi dan mengklasifikasikan limbah B3, yang nantinya akan sangat berguna sebagai informasi penting dalam pengelolaannya. Peraturan yang mengatur tentang pelabelan yaitu Peraturan Menteri Lingkungan Hidup Nomor 3 Tahun 2008 tentang tata cara pemberian simbol dan label bahan berbahaya dan beracun (B3), sedangkan simbol limbah B3 diatur dalam Globally Harmonized System (GHS) tahun 2013

Berdasarkan Kepala Bapedal No. 1 Tahun 1995, setiap tempat penyimpanan sementara (TPS) mengharuskan adanya bak penampung untuk tumpahan. Bak penampungan darurat bertujuan menampung cairan atau bahan yang terkontaminasi oleh limbah B3 dalam jumlah besar agar tidak secara langsung terkontaminasi ke lingkungan. Bak penampungan darurat dirancang kedap air dan mampu menampung bahan yang terkontaminasi dalam jumlah memadai.

\subsection{Ventilasi, Pencahayaan dan house keeping}

Berdasarkan SNI 03-6572-2001 tentang tata cara perancangan sistem ventilasi dan pengkondisian udara pada bangunan gedung, ventilasi merupakan proses untuk mencatu udara segar ke dalam bangunan gedung dalam jumlah yang sesuai kebutuhan, bertujuan untuk memperoleh kenyamanan dan keamanan bagi penghuni dan lingkungan yang berada pada gedung tersebut

Intensitas penerangan di tempat kerja bertujuan untuk memberikan penerangan kepada benda-benda sebagai obyek kerja, peralatan atau mesin dan proses produksi serta lingkungan kerja. Intensitas penerangan merupakan aspek penting di tempat kerja, karena berbagai masalah akan timbul ketika kualitas intensitas penerangan di tempat kerja tidak memenuhi standar. Menghitung indeks ruang (k) sebagai berikut :

$\mathrm{k}=\mathrm{p} \times 1 \mathrm{~h}(\mathrm{p}+\mathrm{l})$

Mencari koefisien pemakaian (Kp) sbb :

$\mathrm{Kp}=\eta \mathrm{p} \times \mathrm{fd}(\mathrm{fd}=0,85)$

Menghitung jumlah sumber

penerangan sbb: $\mathrm{n}=\underline{1,25 \times \mathrm{E} \times \mathrm{A}}$

๖ lampu x Kp

Housekeeping berasal dari kata "house" yang artinya rumah, wisma dan kata "keep" yang artinya menjaga, merawat, atau memelihara. Housekeeping (5S) dikembangkan di Jepang dan merupakan singkatan dari kata-kata jepang yang berawalan dengan huruf S (seiri, seiton, seiso, seiketsu, shitsuke).

A APAR (Alat Pemadam Api Ringan)

Klasifikasi bahaya menurut NFPA 10 tahun 2013 yaitu :

1. Light (low) Hazard. Contoh lokasi ini yaitu ruang kelas, gereja, perkantoran, kamar hotel dan lain-lain.

2. Ordinary (moderate) Hazard. Contoh lokasi ini yaitu ruang makan, took, bengkel, manufaktur ringan dsb.

3. Extra (high) Hazard. Contoh lokasi ini yaitu bengkel kayu, lokasi penyimpanan bahan berbahaya, dsb.

Klasifikasi kebakaran menurut NFPA 102013 :

1 Kebakaran bahan kertas, kayu, kain,plastik (Kelas A)

2 Kebakaran bahan cair atau gas yang mudah terbakar. (Kelas B)

3 Kebakaran instalasi listrik bertegangan. (Kelas C)

4 Kebakaran logam. (Kelas D)

2 Kebakaran pada bahan untuk memasak. (kelas E) [5] 


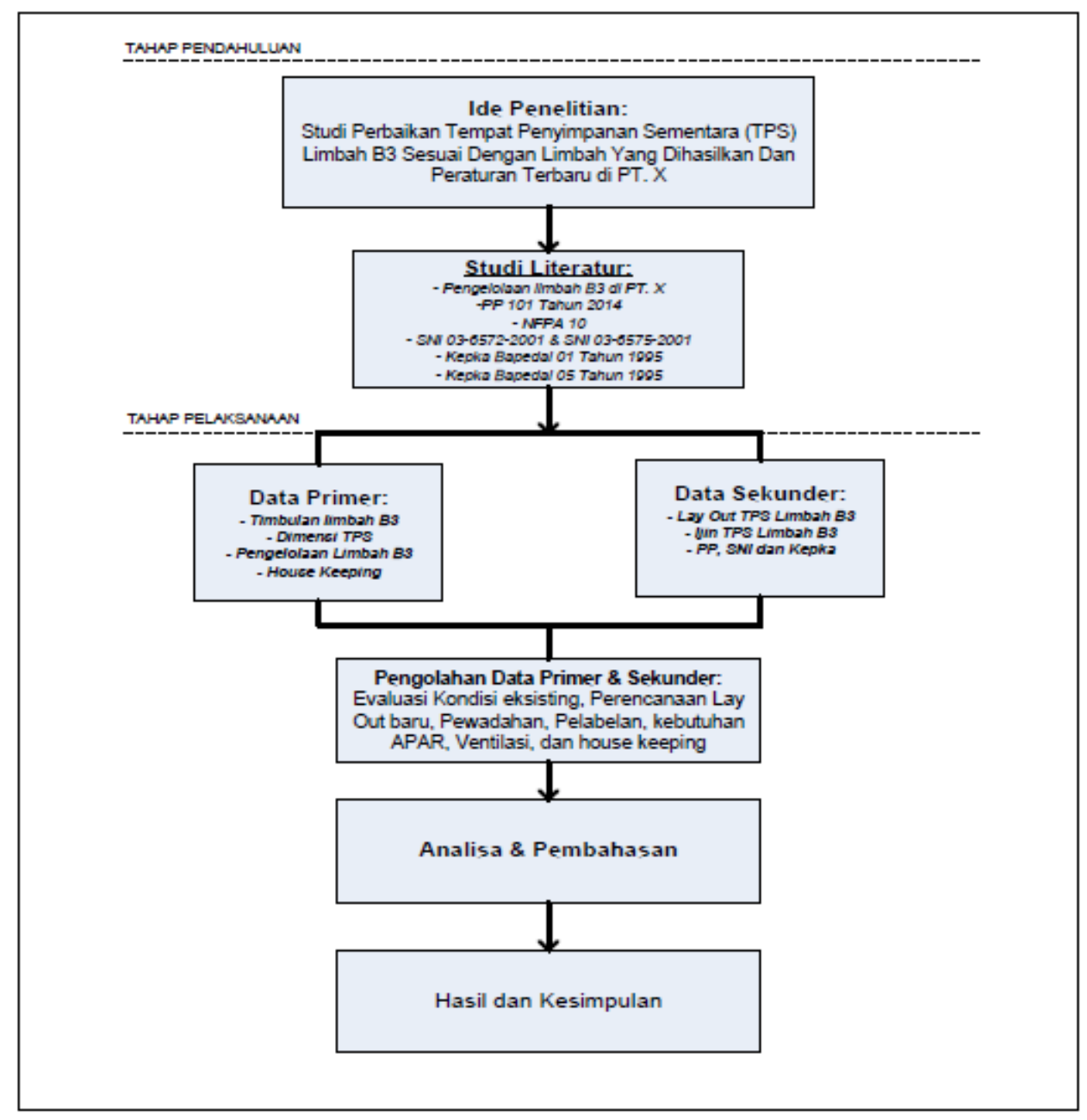

Gambar 1. Judul gambar ditulis dengan besar huruf 10 dan ditulis dari kiri paragraf

\section{HASIL DAN PEMBAHASAN}

\subsection{Evaluasi TPS Limbah B3}

Pada TPS limbah B3 PT X ditemukan ketidaksesuaian dalam pengelolaan limbah B3. Yang terbaru, pada bulan Oktober 2015 beberapa bag sulfatreat di TPS terbakar karena paparan langsung dengan panas sinar matahari. Akibatnya material sulfatreat waste tersebut tercecer ke lingkungan, dan beberapa pohon di sekitar lokasi kejadian tersebut mati. Evaluasi kondisi ketidaksesuaian pada TPS limbah B3 yang merujuk pada PP No.101 Tahun 2014 diantaranya sebagai berikut :

1. Limbah B3 disimpan dalam keadaan bercampur (limbah satu dengan lainnya).

2. TPS dalam keadaan terbuka (tanpa dinding), penerangan minim, ventilasi tidak sesuai standar, bak penampung tidak terawat.

3. Kemasan limbah B3 tidak dilekati simbol dan label.

Tabel 1. pengkodean dan karakeristik limbah B3 yang ada pada TPS limbah B3 PT.X

\begin{tabular}{|c|l|c|c|l|l|}
\hline No & \multicolumn{1}{|c|}{ Limbah B3 } & $\begin{array}{c}\text { Kode } \\
\text { Limbah }\end{array}$ & $\begin{array}{c}\text { Kategori } \\
\text { Bahaya }\end{array}$ & \multicolumn{1}{|c|}{ Sumber } & Karakteristik \\
\hline 1. & Oil Waste & B105d & 2 & Sumber tidak spesifik & Beracun, berbahaya bagi lingkungan \\
\hline 2. & Water Waste & A307-1 & 1 & Sumber spesifik umum & Berbahaya bagi lingkungan \\
\hline 3. & Chemical Waste & A106d & 1 & Sumber tidak spesifik & Berbahaya (harmful), beracun (toxic) \\
\hline 4. & Majun bekas & B110d & 2 & Sumber tidak spesifik & Berbahaya ,beracun, flammable \\
\hline 5. & Sulfatreat Waste & A108d & 2 & Sumber spesifik umum & Flammable \\
\hline 6. & Empty drum waste & B104d & 2 & Sumber tidak spesifik & Korosif \\
\hline
\end{tabular}

Langkah berikutnya yaitu mengumpulkan data sekunder kuantitas limbah B3. Peneliti menggunakan data kuantitas dan jenis limbah B3 mulai Juli 2013 - Januari 2016, terhitung sejak dikeluarkannya Keputusan Bupati Bojonegoro No.188/56/Kep/412.11/2013 tentang izin penyimpanan sementara limbah B3. Setelah dilakukan pengolahan data didapatkan volume setiap jenis limbah B3 yaitu water waste $15,46 \mathrm{~m}^{3}$, oil waste $3,72 \mathrm{~m}^{3}$, solid waste $7,58 \mathrm{~m}^{3}$, chemical waste $3,53 \mathrm{~m}^{3}$, sulfatreat waste $15,24 \mathrm{~m}^{3}$ dan empty drum waste 23 buah. 
Selanjutnya melakukan evaluasi kemasan limbah B3. Kemasan yang digunakan setelah dievaluasi dilengkapi juga dengan simbol dan pelabelan, adapun kapasitas kemasannya yaitu :

1 Water waste dan chemical waste dikemas dalam tote atau IBC tank dengan kapasitas $1,04 \mathrm{~m}^{3}$.

2 Oil waste dikemas dalam drum, kapasitasnya $0,25 \mathrm{~m}^{3}$.

3 Solid waste dikemas dalam bak kayu dengan kapasitas $1,6 \mathrm{~m}^{3}$.

4 Sulfatreat waste dikemas dalam bag sulfatreat dan dimasukkan ke dalam bak kayu, kapasitas $1,075 \mathrm{~m}^{3}$.

1.2. Perhitungan Kebutuhan Kemasan

Menggunakan rumus tentang kebutuhan kemasan. Adapun hasil perhitungan tentang kebutuhan kemasan dapat dilihat pada tabel 2 sebagai berikut :

Tabel 2. Jumlah Kebutuhan Kemasan Limbah B3

\begin{tabular}{|r|r|c|c|c|c|c|}
\hline Ruang Waste & Water & Chemi- cal & Oil & Solid & Sulfa- treat & Empty Drum \\
\hline Jumlah Kemasan & 15 tote & 4 tote & 15 drum & 5 bak & 15 bag & 23 drum \\
\hline
\end{tabular}

1.3. Perhitungan Kebutuhan Jumlah Pallet

Untuk melakukan perhitungan ini menggunakan rumus tentang kebutuhan jumlah pallet. Hasil perhitungan kebutuhan jumlah pallet dijelaskan pada tabel 3 sebagai berikut :

Tabel 3.Jumlah Kebutuhan Jumlah Pallet

\begin{tabular}{|c|c|c|c|c|c|c|}
\hline Ruang Waste & Water & Chemical & Oil & Solid & Sulfatreat & Empty Drum \\
\hline Jumlah Pallet & 15 buah & 4 buah & 4 buah & 5 buah & 15 buah & 6 buah \\
\hline
\end{tabular}

\subsection{Perhitungan Kebutuhan Area / Blok}

Untuk melakukan perhitungan ini menggunakan rumus tentang kebutuhan blok area. Adapun hasil perhitungannya dapat dilihat pada tabel 4 berikut :

Tabel 4. Jumlah Kebutuhan Area / Blok Limbah B3

\begin{tabular}{|c|c|c|c|c|c|c|}
\hline Ruang Waste & Water & Chemical & Oil & Solid & Sulfatreat & Empty Drum \\
\hline $\begin{array}{c}\text { Jumlah } \\
\text { Kemasan }\end{array}$ & 5 blok & 2 blok & 2 blok & 2 blok & 5 blok & 2 blok \\
\hline
\end{tabular}

1.5. Perhitungan Bak Penampungan

Volume bak penampungan dirancang untuk setiap jenis limbah B3 cair, dengan mengalikan volume limbah B3 cair dengan 110\% (Kepka Bapedal No.01 Tahun 1995). Begitu juga dengan kemiringan lantai, bagian dalam lantai dibuat melandai turun ke arah bak penampungan dengan kemiringan 1\%. Adapun hasil perhitungannya dapat dilihat pada tabel 5 berikut :

Tabel 5.Volume dan Dimensi Bak Penampungan

\begin{tabular}{|c|c|c|c|c|c|}
\hline \multirow{2}{*}{ Limbah B3 Cair } & Volume Limbah $\left(\mathbf{m}^{\mathbf{3}}\right)$ & \multirow{2}{*}{ Bak Penampung $\left(\mathbf{m}^{\mathbf{3}}\right)$} & $\mathbf{3}$ & $\mathbf{1}$ & $\mathbf{1}$ \\
\cline { 4 - 6 } & & 17 & 4,8 & 2,1 & $\mathbf{t}$ \\
\hline Water waste & 15,455 & 3,8797 & 3,1 & 0,75 & 1,7 \\
\hline Chemical waste & 3,527 & 4,0887 & 3,25 & 0,75 & 1,7 \\
\hline Oil Waste & 3,717 & & 1,7 \\
\hline
\end{tabular}

Rekomendasi yang diberikan untuk TPS limbah B3 dilakukan perancangan dengan konsep 1 ruangan berisi 1 jenis limbah B3. Dimensi tiap ruangan dapat dilihat pada tabel 6 berikut ini :

Tabel 6. Dimensi Tiap Ruangan TPS Limbah B3

\begin{tabular}{|l|c|c|c|c|}
\hline \multirow{2}{*}{ Ruang } & \multicolumn{3}{|c|}{ Dimensi Ruang (m) } & \multirow{2}{*}{$\operatorname{Luas} \operatorname{Ruangan}\left(\mathbf{m}^{3}\right)$} \\
\cline { 2 - 5 } & $\mathbf{P}$ & $\mathbf{l}$ & $\mathbf{1}$ \\
\hline Water Waste Room & 6,5 & 4,8 & 4,3 & 31,20 \\
\hline Chemical Waste Room & 4,8 & 3,1 & 4,3 & 14,88 \\
\hline Oil Waste Room & 5,1 & 3,25 & 4,3 & 16,58 \\
\hline
\end{tabular}




\begin{tabular}{|l|c|c|c|c|} 
Empty Drum Waste Room & 5,1 & 3,25 & 4,3 & 16,58 \\
\hline Solid Waste & 5,04 & 3,22 & 4,3 & 16,23 \\
\hline Sulfatreat Waste & 6,65 & 4,9 & 4,3 & 32,59 \\
\hline Tools Room & 6,65 & 1,78 & 4,3 & 11,84 \\
\hline
\end{tabular}

1.6. Perancangan Pencahayaan

Pada TPS limbah B3 PT.X belum memiliki sistem pencahayaan yang memadai, karena hanya memanfaatkan tower lamp sebagai penerangan. Peneliti akan merancang sistem pencahayaan (kebutuhan armatur lampu). Adapun langkahnya yaitu :

1. Menentukan jenis sumber penerangan

a. Ruang penyimpanan menggunakan lampu pijar 300W. Arus cahaya tiap armatur $300 \times 13,9$ lumen $=4170$ lumen.

b. Kuat penerangan untuk gudang adalah 100 lux. [6]

2. Menentukan faktor refleksi.
a. Warna langit-langit (R11)
b. Warna dinding $(\mathrm{Rd})$
c. Warna lantai $(\mathrm{Rl})$
$=0,7$ (krem muda)
$=0,5$ (kekuning-kuningan)
$=0,1($ kemerahan $/$ gelap $)$

3. Menghitung indeks ruang.

Dengan menggunakan rumus mencari indeks ruang untuk masing-masing ruangan. Adapun hasil perhitungannya dapat dilihat pada tabel 7 sebagai berikut :

Tabel 7.Indeks Ruang Setiap Ruangan TPS Limbah B3

\begin{tabular}{|c|c|}
\hline Ruang & Indeks Ruang (k) \\
\hline Water Waste Room & 0,642 \\
\hline Chemical Waste Room & 0,5 \\
\hline Oil Waste Room & 0,5 \\
\hline Empty Drum Waste Room & 0,5 \\
\hline Solid Waste & 0,5 \\
\hline Sulfatreat Waste & 0,656 \\
\hline Tools Room & 0,5 \\
\hline
\end{tabular}

4. Menentukan efisiensi penerangan ( $\eta \mathrm{p})$, koefisien pemakaian $(\mathrm{kp})$ dan jumlah armatur pencahayaan.

Dengan melakukan interpolasi data $\mathrm{k}$ dan $\eta \mathrm{p}$ menggunakan tabel efisiensi penerangan lampu pijar 300W. Selanjutnya mencari koefisien pemakaian.

Tabel 8.Nilai $\eta p, k$ dan Jumlah Armatur Penerangan Pada Setiap Ruangan

\begin{tabular}{|l|c|c|c|c|}
\hline \multicolumn{1}{|c|}{ Ruang } & $\mathbf{k}$ & $\eta \mathrm{p}$ & $\mathrm{kp}$ & Jumlah Armatur \\
\hline Water Waste Room & 0,642 & 0,2847 & 0,242 & 4 buah \\
\hline Chemical Waste Room & 0,5 & 0,23 & 0,1955 & 2 buah \\
\hline Oil Waste Room & 0,5 & 0,23 & 0,1955 & 3 buah \\
\hline Empty Drum Waste Room & 0,5 & 0,23 & 0,1955 & 3 buah \\
\hline Solid Waste & 0,5 & 0,23 & 0,1955 & 2 buah \\
\hline Sulfatreat Waste & 0,656 & 0,2896 & 0,2462 & 4 buah \\
\hline Tools Room & 0,5 & 0,23 & 0,1955 & 2 buah \\
\hline
\end{tabular}

4.7 Perancangan Ventilasi

Berdasarkan SNI 03-6572-2001, TPS limbah B3 PT.X termasuk bangunan kelas 7 yaitu bangunan penyimpanan/gudang. Dalam menentukan ventilasi bangunan penyimpanan, yaitu luas ventilasi minimal 10\% terhadap luas lantai dari ruang yang akan diventilasi dan diukur tidak lebih dari 3,6 meter diatas lantai. Perhitungan kebutuhan ventilasi dilihat pada tabel 9 sbb :

Tabel 9.Perhitungan Kebutuhan Ventilasi TPS

\begin{tabular}{|c|c|c|c|c|}
\hline \multirow{2}{*}{ Ruang } & \multirow{2}{*}{$\begin{array}{c}\text { Luas Ruang } \\
\left(\mathbf{m}^{2}\right)\end{array}$} & \multirow{2}{*}{$\begin{array}{c}\text { Luas } \\
\text { Ventilasi }\left(\mathrm{m}^{2}\right) \\
\end{array}$} & \multicolumn{2}{|c|}{ Dimensi Ventilasi } \\
\hline & & & $\mathbf{p}(\mathbf{m})$ & $1(\mathbf{m})$ \\
\hline Water Waste Room & 31,20 & 3,12 & 5,7 & 0,65 \\
\hline Chemical Waste Room & 14,88 & 1,49 & 2,7 & 0,65 \\
\hline Oil Waste Room & 16,58 & 1,66 & 3 & 0,65 \\
\hline Empty Drum Waste Room & 16,58 & 1,66 & 3 & 0,65 \\
\hline Solid Waste & 16,23 & 1,62 & 3 & 0,65 \\
\hline
\end{tabular}




\begin{tabular}{|l|c|c|c|c|}
\hline Sulfatreat Waste & 32,59 & 3,26 & 5 & 0,65 \\
\hline Tools Room & 11,84 & 1,2 & 2,2 & 0,65 \\
\hline
\end{tabular}

4.8. Perancangan APAR

Dalam perancangan APAR TPS limbah B3 PT.X, peneliti menggunakan standar NFPA 13 Tahun 2013. Penempatan APAR harus ditata sedemikian rupa sehingga bagian paling atas (puncaknya) berada pada ketinggian 1,2 $\mathrm{m}$ dari permukaan lantai. Berdasarkan NFPA 10 tahun 2013, untuk menentukan jenis APAR harus mengetahui klasifikasi bahaya dan klasifikasi kebakaran dari suatu ruangan. Klasifikasi bahaya kebakaran pada TPS limbah B3 PT.X dapat dilihat pada tabel 10 sebagai berikut :

Tabel 10. Klasifikasi Kebakaran dan Jenis APAR TPS Limbah B3

\begin{tabular}{|l|c|c|c|}
\hline \multicolumn{1}{|c|}{ Ruangan (Kode) } & $\begin{array}{c}\text { Klasifikasi } \\
\text { Kebakaran }\end{array}$ & Klasifikasi Bahaya & Jenis APAR \\
\cline { 1 - 1 } Water waste (A) & Kelas B & \multirow{2}{*}{ Extra High Hazard } & $\mathrm{CO}_{2}$ \\
\cline { 1 - 1 } Chemical w. (B) & Kelas D & Extra High Hazard & Dry Powder \\
\cline { 1 - 1 } Oil Waste (C) & Kelas A & Extra High Hazard & $\begin{array}{c}\text { Dry Chemical } \\
\text { Powder }\end{array}$ \\
\hline Sulfatreat w. (F) & Solid waste (E) & Kudang (G) &
\end{tabular}

Tabel 11. Jumlah APAR menurut NFPA 10 Tahun 2013

\begin{tabular}{|c|c|c|c|c|}
\hline Ruangan (Kode) & Luas Blok (m2) & Rating & L.Per - lindungan & Jumlah APAR NFPA \\
\hline Water waste (A) & \multirow{3}{*}{62,66} & \multirow{3}{*}{$40-B$} & \multirow{3}{*}{$\begin{array}{l}11.250 \mathrm{ft} 2= \\
1.045,13 \mathrm{~m} 2\end{array}$} & \multirow{3}{*}{$0,06=1$ buah } \\
\hline Chemical w. (B) & & & & \\
\hline Oil Waste (C) & & & & \\
\hline Empty drum (D) & \multirow{2}{*}{49.17} & \multirow{2}{*}{ - } & \multirow{2}{*}{$1.661,06 \mathrm{~m} 2$} & \multirow{2}{*}{$0,03=1$ buah } \\
\hline Sulfatreat $w$. (F) & & & & \\
\hline Solid waste (E) & \multirow{2}{*}{29.85} & \multirow{2}{*}{$4-\mathrm{A}$} & \multirow{3}{*}{$\begin{array}{c}4.000 \mathrm{ft} 2=371,6 \\
\mathrm{~m} 2\end{array}$} & \multirow{2}{*}{$0,08=1$ buah } \\
\hline Gudang & & & & \\
\hline \multicolumn{3}{|c|}{ Total } & & 3 buah \\
\hline
\end{tabular}

Ket : $1 \mathrm{ft}=0.305 \mathrm{~m} ; 1 \mathrm{ft}^{2}=0.0929 \mathrm{~m}^{2}$

Empty drum waste room dan sulfatreat waste room tergolong kelas kebakaran D, sehingga perhitungan kebutuhan jumlah APAR untuk rating D memiliki cara yang berbeda. Menurut NFPA 102013 untuk APAR dengan rating D harus tersedia pada lokasi dimana terdapat logam yang berpotensi mudah terbakar. APAR tersebut diletakkan dengan jarak APAR minimal $23 \mathrm{~m}$ dari sumber bahaya.

\section{KESIMPULAN}

Dari hasil pengolahan dan analisa yang telah dilakukan, maka dalam penelitian ini dapat disimpulkan bahwa :

1. Hasil evaluasi pengelolaan limbah B3 di PT.X yaitu :

a. Timbulan maksimal limbah B3 yang dihasilkan dalam periode penyimpanan bulan Juli 2013-Januari 2016 yaitu : water waste $15,455 \mathrm{~m}^{3}$, oil waste $3,717 \mathrm{~m}^{3}$, solid waste $7,577 \mathrm{~m}^{3}$, chemical waste $3,527 \mathrm{~m}^{3}$, sulfatreat waste $15,243 \mathrm{~m}^{3}$ dan empty drum waste 23 buah. Masing-masing limbah B3 tersebut memiliki karakteristik yang berbeda-beda.

b. Limbah B3 pada TPS dikemas dalam wadah dengan kapasitas tertentu dan dilengkapi dengan simbol serta pelabelan yang sesuai standar. Kemasan yang digunakan adalah :

- Water waste dan chemical waste dikemas dalam tote atau IBC tank dengan kapasitas $1,04 \mathrm{~m}^{3}$.

- Oil waste dikemas dalam drum dengan kapasitas $0,25 \mathrm{~m}^{3}$.

- Solid waste dikemas dalam bak kayu dengan kapasitas $1,6 \mathrm{~m}^{3}$.

- Sulfatreat waste dikemas dalam bag sulfatreat yang dimasukkan ke dalam bak kayu dengan kapasitas $1,075 \mathrm{~m}^{3}$.

c. TPS limbah B3 PT.X memiliki dimensi lahan yang digunakan berukuran $25,5 \mathrm{mx} 7 \mathrm{~m}$, sehingga dalam redesign TPS ini harus mempertimbangkan dimensi total TPS tersebut.

d. Sarana prasarana yang dirancang dalam evaluasi TPS limbah B3 sebagai berikut : 
- Bak penampungan dirancang untuk setiap jenis limbah B3 cair. Volume bak penampungan water waste adalah $17 \mathrm{~m}^{3}$, volume bak penampungan chemical waste yaitu $3,88 \mathrm{~m}^{3}$ dan untuk volume bak penampungan oil waste adalah $4,09 \mathrm{~m}^{3}$.

- Perancangan penerangan pada TPS limbah B3 menggunakan 20 buah armatur (lampu pijar 300 Watt) untuk ruang penyimpanan.

- Perancangan sistem ventilasi menggunakan ventilasi alami, luas ventilasi yang dibutuhkan minimal $10 \%$ terhadap luas lantai ruangan tersebut. Sehingga setiap ruangan memiliki luas ventilasi yang berbeda-beda, dan dari perhitungan didapatkan total seluruh luas bukaan yaitu $14,01 \mathrm{~m}^{2}$.

- Hasil perancangan APAR (NFPA 10 Tahun 2013) yang harus tersedia pada TPS limbah B3 yaitu 3 buah APAR ( $\mathrm{CO}_{2}$, dry powder dan dry chemical powder).

2. Housekeeping di TPS limbah B3 PT.X perlu dilakukan untuk mengatur atau mengelola tempat kerja menjadi lebih baik secara berkelanjutan. Dengan demikian dapat mengurangi bahaya di tempat kerja, meningkatkan kenyamanan dan produktifitas serta menghilangkan pemborosan di tempat kerja.

\section{DAFTAR PUSTAKA}

[1] J. S. SOEMIRAT, Kesehatan Lingkungan. Yogyakarta: Gajah Mada University Press, 2002.

[2] PEMERINTAH KABUPATEN BOJONEGORO, Keputusan Bupati Bojonegoro No.188/56/Kep/412.11/2013 tentang Izin Penyimpanan Sementara Limbah Bahan Berbahaya dan Beracun Kepada Mobil Cepu Limited (MCL). 2013.

[3] PEMERINTAH REPUBLIK INDONESIA, Peraturan Pemerintah Nomor 101 Tahun 2014 tentang Pengelolaan Limbah Bahan Berbahaya dan Beracun. Indonesia, 2014.

[4] Bapedal, Keputusan Kepala Bapedal No.01Tahun 1995 tentang Tata Cara dan Persyaratan Teknis Penyimpanan Serta Pengumpulan Limbah Bahan Berbahaya dan Beracun. Indonesia, 1995.

[5] "NFPA 10 Tahun 2013 tentang standart portable for fire extinguisher."

[6] BADAN STANDART NASIONAL, SNI 03-6572-2001 tentang Tata Cara Perancangan Sistem Ventilasi dan Pengkondisian Udara Pada Bangunan Gedung. Jakarta: Badan Standardisasi Nasional, 2001. 